Z. Klin: Chem. Klin. Biochem.

12. Jg. 1974, S. $327-335$

\title{
Zur Biochemie der Spurenelemente Zink, Kupfer, Mangan, Molybdän, Chrom und Kobalt: Verteilung, Bindung und Regulation durch Nebennierenrinden-Hormone
}

\author{
Von T. Günther, B. Ruhe, J. Schmalbeck und Nahib Tehrani \\ Zentralinstitut für Biochemie und Biophysik und Physiologisch-Chemisches Institut der Freien Universität Berlin
}

(Eingegangen am 23. Oktober 1973/1. März 1974)

\begin{abstract}
Die Spurenelemente $\mathrm{Cu}, \mathrm{Mn}, \mathrm{Mo}$ und Co sind in der Leber charakteristisch auf die Zellfraktionen, Kerne, Mitochondrien, Mikrosomen und Cytoplasma, verteilt. Bei den einzelnen Spurenelementen sind der Gehalt und die Verteilung nach Adrenalektomie in unterschiedlicher Weise geändert. Der nach Adrenalektomie erhöhte Cu-Gehalt der Leber wird durch Cortison normalisiert.

Die untersuchten Spurenelemente werden im Cytoplasma zumeist an drei Fraktionen von Proteinen gcbunden. Diese haben ein Molgewicht von etwa 120 000, 30000 und 9 000. Die Verteilung der Metallionen auf die Proteinfraktionen weist eine typische Zeitabhängigkeit auf, die durch den intrazellulären turnover der Spurenelemente bedingt ist. Durch vergleichende Inkubation von Cytoplasma mit radioaktiven Spurenelementen in vitro wurde wahrscheinlich gemacht, daß einige Spurenelemente bei der Synthese ihrer Bindungsproteine irreversibel eingebaut werden. Für die Bindungsproteine wird eine Speicher- und Schutzfunktion diskutiert.

Nach Zugabe von radioaktiven Spurenelementen zu Serum und dessen elektrophoretischer Auftrennung wurden Co im Albumin, Mn im $\beta$-Globulin (Transferrin), Zn im $\alpha_{2}$-Globulin und $\mathrm{Cr}$ im $\alpha$-Globulin und $\beta$-Globulin (Transferrin) gefunden. Nach Adrenalektomie war der Gehalt an $\mathrm{Cu}, \mathrm{Mn}$ und $\mathrm{Cr}$ im Serum erhöht, der an Mo erniedrigt.
\end{abstract}

\section{Biochemistry of the trace elements $\mathrm{Zn}, \mathrm{Cu}, \mathrm{Mn}, \mathrm{Cr}$ and $\mathrm{Co}$ : Distribution, binding and regulation by adrenal hormones}

In the liver, the trace elements $\mathrm{Cu}, \mathrm{Mn}, \mathrm{Mo}$ and $\mathrm{Co}$ show a characteristic distribution between nucleus, mitochondria, microsomes and cytoplasm. The concentration and distribution of each trace element show specific changes after adrenalectomy. The increase in the concentration of $\mathrm{Cu}$ in the liver after adrenalectomy is normalized by cortisone.

In the cytoplasm, the trace elements are bound by, at the most, three different protein fractions: molecular weights approximately 120000,30000 and 9000 . The distribution of the metal ions amongst these protein fractions shows a typical time dependence, which results from the intracellular turnover of the trace elements. From comparative incubations of cytoplasm with radioactive trace elements in vitro, it seems likely that some trace elements become irreversibly incorporated during the synthesis of their binding proteins. A storage and protection function is suggested for the binding proteins.

After the addition of radioactive trace elements to serum and electrophoretic separation, Co was bound in the albumin fraction, Mn in the $\beta$-globulin (transferrin), $\mathrm{Zn}$ in the $\alpha_{2}$-globulin and $\mathrm{Cr}$ in the $\alpha$-globulin and $\beta$-globulin (transferrin). After adrenalectomy, the concentrations of $\mathrm{Cu}, \mathrm{Mn}$ and $\mathrm{Cr}$ in the serum were increased, and Mo was decreased.

Spurenelemente wurden in zunehmendem Maße als Bestandteile von Enzymen identifiziert $(1,2)$. Dies dürfte ihre wesentliche biologische Funktion sein.

Der Gehalt an Spurenelementen in einem Organ ist jedoch höher als sich durch ihr Vorkommen in Enzymen erklären läßt. Vom Zn z. B. sind nicht mehr als $5 \%$ in Enzymen (Dehydrogenasen, Carboanhydrase, alkalische Phosphatase) enthalten (3). Der Rest ist wegen der guten chelatbildenden Eigenschaften dieser Elemente in der Zelle gebunden, z. B. an Proteine. Deshalb führt wahrscheinlich $\mathrm{Zn}$-arme Ernährung auch kaum zu einer Aktivitätsabnahme Zn-enthaltender Enzyme (4). Der Transport der resorbierten Spurenelemente erfolgt im Plasma ebeníalls nach Bindung an Proteine, wobei für die verschiedenen Elemente unterschiedliche TransportProteine verwendet werden. Nach ihrem Transport durch die Zellmembran werden radioaktiv markierte Spurenelemente wie ${ }^{67} \mathrm{Cu},{ }^{65} \mathrm{Zn}$ (oder ${ }^{109} \mathrm{Cd}$ ) $(5-8)$ an Proteine gebunden und von diesen später in andere
Bindungsproteine des Cytoplasmas überführt. Zusätzlich werden die Spurenelemente in den übrigen Zellorganellen (Kern, Mitochondrien und Mikrosomen) gebunden, in denen sie je nach Element und Zellfraktion in unterschiedlicher Menge nachweisbar sind (9).

Die Spurenelemente des Organismus befinden sich offenbar in einem regulierbaren dynamischen Gleichgewicht, denn der Zn-Gehalt der Leber z. B. ist nach Adrenalektomie erhöht und wird durch Glucocorticoide wieder normalisiert (10).

Durch die Entwicklung der Atomabsorptionsspektrophotometrie (Graphitrohrküvette) ist die Nachweisgrenze erheblich gesenkt worden, so daß wir unsere früheren Untersuchungen am $\mathrm{Zn}(10)$ auf weitere Spurenelemente, die in geringerer Konzentration vorkommen, ausdehnen konnten.

Es wurde damit auch möglich, die Verteilung von Spurenelementen auf die Zellorganellen zu bestimmen. 
Zur weiteren Aufschlüsselung der Verteilung wurden die mit radioaktiven Spurenelementen markierten Proteine des Cytoplasmas aufgetrennt.

Im einzelnen wurden bestimmt:

1. Gehalt im Organ

\begin{tabular}{|c|c|c|c|c|}
\hline $\mathrm{Mn}$ & $\mathrm{Cu}$ & Mo & $\mathrm{Cr}$ & Co \\
\hline $\mathrm{Mn}$ & $\mathrm{Cu}$ & Mo & - & Co \\
\hline In & - & Mo & - & 0 \\
\hline
\end{tabular}

3. Radionuklide im Cytoplasma nach i.v.-Injektion

4. Radionuklide im Cytoplasma nach in vitro-Zugabe

5. Radionuklide im Cytoplasma nach Vorbehandlung mit Cd

6. Radionuklide im Serum nach in vitro-Zugabe

$\mathrm{Mn}-\quad \mathrm{Cr}$ Co $\mathrm{Zn}$

Methodik

Die Versuche wurden mit 200-250 g schweren Wistarratten durchgeführt, die Altromin und Leitungswasser ad libitum erhielten. Die Ratten wurden in Äthernarkose transabdominell adrenalektomiert. Je 6 der adrenalektomierten Tiere wurden mit $5 \mu \mathrm{g} D, L$-Aldosteronacetat/Tag bzw. $8 \mathrm{mg}$ Cortisonacetat/ Tag - insgesamt 7 Tage lang - substituiert.

Die Vorbehandlung der Tiere, die Entnahme und Gefriertrocknung der Organe wurde früher ausführlich beschrieben (11). Bei Vorbehandlung mit $\mathrm{Cd}^{2+}$ wurden den Tieren $24 \mathrm{~h}$ vor dem Versuch (Injektion der Radionuklide) $22 \mu \mathrm{mol} / \mathrm{kg}$ Gewicht $\mathrm{CdCl}_{2}$ in $1 \mathrm{ml} 9 \mathrm{~g} / 1 \mathrm{NaCl}$ i. p. injiziert.

\section{Veraschung}

Je nach Gehalt wurden 4-280 mg vom Trockenpulver der Organe oder Zellfraktionen bzw. bei Mn, Mo und Cr 10-70 mg gefriergetrocknetes Serum von Tieren, denen keine Radionuklide injiziert worden waren, in Durangläsern ( $\phi 12 \mathrm{~mm}$, Höhe $10 \mathrm{~mm}$ ) bei 300-400 Watt und 1 Torr $\mathrm{O}_{2} 12 \mathrm{~h}$ lang im low temperature asher 505 der Firma Tracerlab verascht. Der Rückstand wurde in $0,1 \mathrm{~mol} / 1 \mathrm{HCl}$ aufgenommen.

A tomabsorptionsspektrophotometrie

Die quantitative Bestimmung der Spurenelemente wurde mit dem Gerät der Firma Perkin-Elmer, Modell 300, mit Graphitrohrküvette und Deuteriumkompensator durchgeführt.

Die eingebrachten Proben $(10-50 \mu \mathrm{l})$ wurden bei $100^{\circ} \mathrm{C}$ für

$20-50$ s getrocknet und bei $1000^{\circ} \mathrm{C}$ für $60-90 \mathrm{~s}$ thermisch zersetzt.

Die Atomisierung erfolgte bei der Bestimmung von $\mathrm{Co}, \mathrm{Cr}, \mathrm{Cu}$ und $\mathrm{Mn}$ bei etwa $2400^{\circ} \mathrm{C}$ und bei der Bestimmung von Mo bei etwa $2500^{\circ} \mathrm{C}$.
Die verwendeten Wellenlängen waren bei Co $240,7 \mathrm{~nm}, \mathrm{Cr} 357,8$ $\mathrm{nm}, \mathrm{Cu} 324,7 \mathrm{~nm}, \mathrm{Mn}$ 279,5 nm und Mo 313,3 nm. Die Eichlösungen wurden aus p. a.-Reagenzien in $0,1 \mathrm{~mol} / 1 \mathrm{HCl}$. hergestellt.

Zellfraktionierung

Zur Zellfraktionierung wurde ein 10 proz. Homogenat der frisch entnommenen Lebern in gekühlter $0,25 \mathrm{~mol} / 1$ Saccharose nach Schneider und Hogeboom (12) fraktioniert zentrifugiert, jeweils einmal gewaschen und gefriergetrocknet. Der Gehalt an Spurenelementen wurde auf den Proteingehalt der Zellfraktionen bezogen, der nach Kjehldahl bestimmt wurde.

\section{Gelfiltration}

Zur Untersuchung des Verhaltens der Spurenelemente im Cytoplasma wurden die Radionuklide in neutraler, isotoner $\mathrm{NaCl}-\mathrm{Lösung}$ intravenös injiziert. (Dosierung s. Tab. 1.) $30 \mathrm{~min}$ und $24 \mathrm{~h}$ p. i. wurden den Tieren in Äthernarkose Blut zur Serumgewinnung und die Leber entnommen. Die Leber wurde in $0,25 \mathrm{~mol} / 1$ Saccharose homogenisiert und die Überstandsfraktion durch $60 \mathrm{~min}$. Zentrifugiéren bei $100000 \mathrm{~g}$ gewonnen.

Parallel hierzu wurde die Überstandsfraktion vọn normalen Ratten, denen keine Radionuklide injiziert wurden, $60 \mathrm{~min}$ bei $37^{\circ} \mathrm{C}$ mit trägerfreiem Radionuklid gemäß Tabelle 1 unter Schütteln inkubiert.

Jeweils $1 \mathrm{ml}$ diєser Überstandsfraktionen wurde auf einer Säule (Firma Pharmacia, $92 \mathrm{~cm} \times 1,8 \mathrm{~cm}, \mathrm{~V}_{0}=60,4 \mathrm{ml}$ ), die mit Sephadex G 100 gefullt war, mit 0,05 mol/1 Tris $\mathrm{Cl}, \mathrm{pH} 7,5$ in 0,1 $\mathrm{mol} / \mathrm{l} \mathrm{NaCl}$ bei Raumtemperatur $\left(22^{\circ}\right)$ getrennt. Die Durchflußgeschwindigkeit betrug $0,2 \mathrm{ml} / \mathrm{min}$. Fraktionen zu je $2 \mathrm{ml}$ wurden aufgefangen.

In diesen Fraktionen wurde die Radioaktivität im NaJ-BohrlochKristall (Firma Frieseke-Berthold) und der Proteingehalt photometrisch bei $278 \mathrm{~nm}$ gemessen.

\section{Serumelektrophorese}

Serum von normalen und adrenalektomierten Ratten wurde $60 \mathrm{~min}$ bei $25^{\circ} \mathrm{C}$ mit $50 \mu \mathrm{Ci} / \mathrm{ml}$ des trägerfreien Radionuklids geschüttelt. Die Trennung der Serumproteine erfolgte auf Celluloseacetatmembranen in $0,07 \mathrm{~mol} / 1$ Veronalpuffer $\mathrm{pH} 8,6$ bei einer Spannung von 200 V. Die Elektrophorese wurde beendet, wenn die Albuminfraktion etwa $8 \mathrm{~cm}$ gewandert war. Die Radioaktivität der Elektropherogramme wurde im Dünnschichtscanner der Firma Frieseke und Berthold ausgemessen. Die Proteinbanden wurden zum Vergleich mit Ponceau S angefärbt und photometriert.

\section{Ergebnisse und Diskussion}

Einfluß der Nebennierenrinde auf den Gehalt an $\mathrm{Cu}, \mathrm{Mn}, \mathrm{Mo}$ und $\mathrm{Cr}$ in Leber; Muskel und Serum (Tab. 2)

Wie früher (10) beim $\mathrm{Zn}$ gefunden, wird auch der $\mathrm{Ge}$ halt an $\mathrm{Cu}$ in der Muskulatur von der Nebennierenrinde nicht beeinflußt. In der Leber dagegen sind der $\mathrm{Zn}$ - und Cu-Gehalt nach Adrenalektomie erhöht. Substitution mit Cortison, nicht aber mit Aldosteron, bewirkt ihre

Tab. 1. Verwendete Radionuklide und deren Dosierung.

Die Radionuklide wurden vom Radiochemical Centre, Amersham, bezogen.

\begin{tabular}{|c|c|c|c|c|c|}
\hline \multirow[t]{2}{*}{ Radionuklide } & \multirow[t]{2}{*}{ gelöst in } & \multirow[t]{2}{*}{$\begin{array}{l}\text { spez. Akt. mCi/mg } \\
\text { Element }\end{array}$} & \multicolumn{2}{|c|}{$\begin{array}{l}\text { i. v. Injektion } \\
(\mu \mathrm{Ci} / \text { Ratte })\end{array}$} & \multirow[t]{2}{*}{$\begin{array}{l}\text { Inkubation in } \\
\text { vitro }(\mu \mathrm{Ci} / \mathrm{ml})\end{array}$} \\
\hline & & & $30 \mathrm{~min}$ & $24 \mathrm{~h}$ & \\
\hline $\begin{array}{l}{ }^{54} \mathrm{MnCl}_{2} \\
{ }^{65} \mathrm{ZnCl}_{2} \\
{ }^{60} \mathrm{CoCl}_{2} \\
{ }^{51} \mathrm{CrCl}_{3} \mathrm{Cl}_{3} \\
\left(\mathrm{NH}_{4}\right){ }_{2}^{99} \mathrm{MoO}_{4}\end{array}$ & $\begin{array}{l}0,1 \mathrm{~mol} / 1 \mathrm{HCl} \\
0,1 \mathrm{~mol} / 1 \mathrm{HCl} \\
\mathrm{H}_{2} \mathrm{O} \\
9 \mathrm{~g} / 1 \mathrm{NaCl}, \mathrm{pH} 3-4 \\
\mathrm{H}_{2} \mathrm{O}\end{array}$ & $\begin{array}{l}>100 \\
>100 \\
50-150 \\
50-150 \\
3-6\end{array}$ & $\begin{array}{r}60 \\
100 \\
60 \\
\overrightarrow{375}\end{array}$ & $\begin{array}{r}60 \\
150 \\
85 \\
- \\
375\end{array}$ & $\begin{array}{l}0,13 \\
0,25 \\
0,1 \\
0,1 \\
-\end{array}$ \\
\hline
\end{tabular}


Tab. 2. Wirkung von Nebennierenrinden-Hormonen auf den Gehalt an $\mathrm{Mn}, \mathrm{Cu}, \mathrm{Mo}$ und $\mathrm{Cr}$ in Leber, Muskel und Serum von je $6 \mathrm{Ratten}$. Mittelwert \pm mittlerer Fehler des. Mittelwertes.

\begin{tabular}{|c|c|c|c|c|c|c|c|c|c|c|}
\hline & \multicolumn{4}{|c|}{ Leber } & \multicolumn{2}{|c|}{ Muskel } & \multicolumn{4}{|c|}{ Serum } \\
\hline & $\mathbf{M n}$ & $\mathrm{Cu}$ & Mo & $\mathrm{Cr}$ & $\mathbf{M n}$ & $\mathrm{Cu}$ & Mn & $\mathrm{Cu}$ & Mo & $\mathrm{Cr}$ \\
\hline & \multicolumn{6}{|c|}{ (umol/kg Trockensubstanz) } & \multicolumn{4}{|c|}{$(\mu \mathrm{mol} / \mathrm{l})$} \\
\hline Normale Tiere & $\begin{array}{l}166 \\
\pm 3,5\end{array}$ & $\begin{array}{l}225 \\
\pm 4,9\end{array}$ & $\begin{array}{l}19,0 \\
\pm 1,2\end{array}$ & $\begin{array}{l}5,0 \\
\pm 0,5\end{array}$ & $\begin{array}{l}12,0 \\
\pm 0,2\end{array}$ & $\begin{array}{l}97,6 \\
\pm 6,3\end{array}$ & $\begin{array}{l}0,149 \\
\pm 0,040\end{array}$ & $\begin{array}{l}16,1 \\
\pm 0,4\end{array}$ & $\begin{array}{l}0,064 \\
\pm 0,009\end{array}$ & $\begin{array}{l}1,16 \\
\pm 0,22\end{array}$ \\
\hline $\begin{array}{l}\text { Adrenalektomierte } \\
\text { Tiere }\end{array}$ & $\begin{array}{l}107 \\
\pm 6,7\end{array}$ & $\begin{array}{l}300 \\
\pm 7,6\end{array}$ & $\begin{array}{l}18,8 \\
\pm 1,0\end{array}$ & $\begin{array}{l}4,7 \\
\pm 1,0\end{array}$ & $\begin{array}{l}10,4 \\
\pm 0,3\end{array}$ & $\begin{array}{l}105 \\
\pm 8,9\end{array}$ & $\begin{array}{l}0,214 \\
\pm 0,033\end{array}$ & $\begin{array}{l}35,5 \\
\pm 2,3\end{array}$ & $\begin{array}{l}0,046 \\
\pm 0,004\end{array}$ & $\begin{array}{l}2,00 \\
\pm 0,22\end{array}$ \\
\hline $\begin{array}{l}\text { Adrenalektomierte } \\
\text { Tiere + Aldosteron }\end{array}$ & $\begin{array}{l}120 \\
\pm 5,7\end{array}$ & $\begin{array}{l}355 \\
\pm 10,5\end{array}$ & $\begin{array}{l}21,1 \\
\pm 0,6\end{array}$ & $\begin{array}{l}1,8 \\
\pm 0,1\end{array}$ & $\begin{array}{l}9,9 \\
\pm 0,5\end{array}$ & $\begin{array}{l}94,1 \\
\pm 7,2\end{array}$ & - & - & - & - \\
\hline $\begin{array}{l}\text { Adrenalektomierte } \\
\text { Tiere + Cortison }\end{array}$ & $\begin{array}{l}102 \\
\pm 4,9\end{array}$ & $\begin{array}{l}236 \\
\pm 12,0\end{array}$ & $\begin{array}{l}11,6 \\
\pm 0,5\end{array}$ & $\begin{array}{l}3,0 \\
\pm 0,2\end{array}$ & $\begin{array}{l}10,5 \\
\pm 0,6\end{array}$ & $\begin{array}{l}105 \\
\pm 5,0\end{array}$ & - & - & - & - \\
\hline
\end{tabular}

Normalisierung. Diese gleichsinnige Beeinflussung von $\mathrm{Zn}$ und $\mathrm{Cu}$ mag darauf beruhen, daß beide Elemente im Cytoplasma der Leberzelle z. T. von den gleichen Proteinen gebunden werden können (s. unten). Für Metallothionein ist dies erwiesen $(7,13,14)$.

Mn wird in Leber und Muskel durch NebennierenrindenHormone beeinflußt, die Veränderungen im Skelettmuskel sind jedoch geringer. Nach Adrenalektomie ist der Gehalt an Mn intrazellulär erniedrigt und wird weder durch Aldosteron noch durch Cortison allein in der gewählten Dosierung normalisiert. Der Gehalt an Mo und $\mathrm{Cr}$ ist nach Adrenalektomie unverändert.

Der Gehalt an Mo wird aber durch Cortison, der an $\mathrm{Cr}$ durch Aldosteron gesenkt. Dies könnte auf unphysiologischer Dosierung beruhen.

Im Serum war nach Adrenalektomie der Gehalt an $\mathrm{Mn}$, $\mathrm{Cu}$ und $\mathrm{Cr}$ angestiegen, der an Mo gesunken. Der CoGehalt war so niedrig, daß er nicht exakt meßbar war.
$\mathrm{Cu}$ und $\mathrm{Zn}$ verhalten sich demnach im Serum im Gegensatz zur Leber nicht gleichartig. Dies ist wahrscheinlich darauf zurückzuführen, daß $\mathrm{Zn}$ und $\mathrm{Cu}$ im Serum an verschiedene Bindungsproteine gebunden werden. $\mathrm{Zn}$ wird an ein $\alpha_{2}$-Globulin (15), $\mathrm{Cu}$ an Caeruloplasmin (1) und Transferrin ( $\beta_{1}$-Globulin) (16) gebunden.

Offen bleibt, ob die von Nebennierenrinden-Hormonen abhängige Verteilung der Spurenelemente zwischen Intrazellulärraum und Serum durch einen geänderten Gehalt an Bindungsproteinen in diesen Räumen bedingt ist, oder ob der Transport der Spurenelemente in die Zelle und heraus durch Hormone beeinflußt wird.

Intrazelluläre Verteilung bei normalen und adrenalektomierten Ratten

Um zu sehen, in welcher Zellfraktion eine Änderung des Gehalts an Spurenelementen erfolgt, untersuchten wir ihre subzelluläre Verteilung (Tab. 3). Die Zunahme

Tab. 3. Subzelluläre Verteilung von $\mathrm{Mn}, \mathrm{Cu}, \mathrm{Mo}$ und $\mathrm{Co}$ in den Lebern von normalen und adrenalektomierten Ratten. Mittelwert \pm mittlerer Fehler des Mittelwertes von jeweils Fraktionierungen.

\begin{tabular}{|c|c|c|c|c|c|c|c|c|}
\hline & \multicolumn{4}{|c|}{ Normale Tiere } & \multicolumn{4}{|c|}{ Adrenalektierte Tiere } \\
\hline & $\mathrm{Cu}$ & Mn & Mo & Co & $\mathrm{Cu}$ & Mn & Mo & Co \\
\hline \multicolumn{9}{|c|}{ ( $\mu \mathrm{mol} / \mathrm{kg}$ Protein) } \\
\hline Gesamtleber & $\begin{array}{l}357,8 \\
\pm 8,6\end{array}$ & $\begin{array}{l}268,2 \\
\pm 10,2\end{array}$ & $\begin{array}{l}23,9 \\
\pm 0,6\end{array}$ & $\begin{array}{l}3,2 \\
\pm 0,1\end{array}$ & $\begin{array}{l}435,5 \\
\pm 16,4\end{array}$ & $\begin{array}{l}168,3 \\
\pm 8,1\end{array}$ & $\begin{array}{l}26,5 \\
\pm 1,3\end{array}$ & $\begin{array}{l}5,5 \\
\pm 0,4\end{array}$ \\
\hline Kerne & $\begin{array}{l}500,0 \\
\pm 18,4\end{array}$ & $\begin{array}{l}468,8 \\
\pm 11,2\end{array}$ & $\begin{array}{l}24,4 \\
\pm 0,7\end{array}$ & $\begin{array}{l}4,1 \\
\pm 0,6\end{array}$ & $\begin{array}{l}537,5 \\
\pm 10,1\end{array}$ & $\begin{array}{l}337,0 \\
\pm 18,5\end{array}$ & $\begin{array}{l}35,9 \\
\pm 1,5\end{array}$ & $\begin{array}{l}6,4 \\
\pm 0,4\end{array}$ \\
\hline Mitochondrien & $\begin{array}{l}414,8 \\
\pm 19,7\end{array}$ & $\begin{array}{l}490,4 \\
\pm 29,7\end{array}$ & $\begin{array}{l}45,9 \\
\pm 5,6\end{array}$ & $\begin{array}{l}7,0 \\
\pm 1,2\end{array}$ & $\begin{array}{l}264,4 \\
\pm 12,4\end{array}$ & $\begin{array}{l}206,3 \\
\pm 11,6\end{array}$ & $\begin{array}{l}24,0 \\
\pm 2,1\end{array}$ & $\begin{array}{l}20,7 \\
\pm 1,2\end{array}$ \\
\hline Mikrosomen & $\begin{array}{l}152,6 \\
\pm 17,6\end{array}$ & $\begin{array}{l}175,2 \\
\pm 13,5\end{array}$ & $\begin{array}{l}13,4 \\
\pm 1,4\end{array}$ & $\begin{array}{l}2,4 \\
\pm 0,2\end{array}$ & $\begin{array}{l}152,8 \\
\pm 5,0\end{array}$ & $\begin{array}{l}152,0 \\
\pm 4,0\end{array}$ & $\begin{array}{l}18,6 \\
\pm 0,8\end{array}$ & $\begin{array}{l}5,1 \\
\pm 0,3\end{array}$ \\
\hline Überstand & $\begin{array}{l}352,3 \\
\pm 27,1\end{array}$ & $\begin{array}{l}49,0 \\
\pm 6,9\end{array}$ & $\begin{array}{l}65,4 \\
\pm 4,9\end{array}$ & $\begin{array}{l}3,2 \\
\pm 0,3\end{array}$ & $\begin{array}{l}576,6 \\
\pm 19,8\end{array}$ & $\begin{array}{l}56,9 \\
\pm 2,7\end{array}$ & $\begin{array}{l}41,2 \\
\pm 2,0\end{array}$ & $\begin{array}{l}3,3 \\
\pm 0,7\end{array}$ \\
\hline
\end{tabular}


des Cu-Gehal ts nach Adrenalektomie, die auch von anderen gefunden wurde (17), ist auf eine Zunahme des $\mathrm{Cu}$ im Cytoplasma zurückzuführen. Diese ist so hoch, daß dic Abnahme des $\mathrm{Cu}$ in den Mitochondrien überkompensiert wird.

Die Abnahme des Mn-Gehalts erstreckt sich auf die Kerne, Mikrosomen und besonders die Mitochondrien.

Der Gehalt an Mo im Gesamtorgan bleibt zwar konstant, es gibt ater innerhalb der Zellfraktionen Verschiebungen. Der Mo-Gehalt in den Kernen und Mikrosomen nimmt $\mathrm{zu}$, in Mitochondrien und Cytoplasma nimmt er ab.

Der Gehalt an Co nimmt nach Adrenalektomie zu. Dicse Zunahme zeigt sich an den Kernen und Mikrosomen und in besonders hohem Maße an den Mitochondrien, nicht aber im Cytoplasma.

Jedes der Elemente zeigt also eine charakteristische Verteilung auf die Zellfraktionen. Diese sind bei normalen Ratten von Thiers und Vallee (9) für $\mathrm{Cu}$ und $\mathrm{Mn}$ ermittelt worden. Unsere entsprechenden Werte für $\mathrm{Mn}$ stimnen mit diesen gut überein. Beim $\mathrm{Cu}$ ist die Übereinstimmung weniger gut. Tabelle 3 zeigt, daß von $\mathrm{Cu}$, Mo und Co ein beträchtlicher Teil im Cytoplasma liegt. Vom Mn wird nur wenig im Cytoplasma und ein großer Teil in den Kernen und Mitochondrien gefunden. Dies läßt sich mit der starken Komplexbindung des $\mathrm{Mn}$ an Nucleinsäuren (17) und dem aktiven Transport von $\mathrm{Mn}$ in Mitochondrien (18) erklüren. Darüberhinaus gibt es für einzelne Elemente in den verschiedenen Zellfraktionen spezielle Bindungsproteine, für $\mathrm{Cu}, z$. B. Hepatocuprein, Mitochondrocuprein und Metallothionein (19).

Neben derartigen, unterschiedlich lokalisierten intrazellulären Metalloproteinen gibt es noch unterschiedlich auf die Zell fraktionen verteilte Metalloenzyme. Ihre Menge und ihr Beitrag zum spezifischen Verteilungsmuster muß noch bestimmt werden.

Eine Änderung im Gesamtgehalt eines Spurenelements geht nur mit dem Gehalt in den Zellkernen parallel. Dies ist mit Komplexbildung an Nucleinsäuren erklärbar. In den anderen Zellfraktionen findet man keine gleichsinnigen Veränderungen. Die Nebennierenrinden-Hormone haben hier bei den einzelnen Elementen einen unterschiedlichen Effekt. An den Mitochondrien waren die Veränderungen am stärksten.

Verhalten der Spurenelemente im Cytoplasma nach i. v. Injektion radioaktiver Nuklide

Wir haben uns wegen der einfachen Gewinnung und des nativen Zustandes der gelösten Bindungsproteine auf die Überstandsfraktion (Cytoplasma) beschränkt. Eine komplette Analyse der Wirkung der Nebennierenrinden-Hormone, die alle Zellorganellen umfaßt, ist deshalb nicht möglich.

Owen (19) fand $30 \mathrm{~min}$ nach i. v. Injektion von ${ }^{67} \mathrm{Cu}$ im Cytoplasma $3 \mathrm{Cu}$-Proteine mit einem Molgewicht von
150000,31000 und 11000 . Das Verhältnis ihrer

${ }^{67} \mathrm{Cu}$-Aktivität verhielt sich $30 \mathrm{~min}$ p. i. wie: $21,0: 37,6$ :

41,5. $24 \mathrm{~h}$ nach der Injektion verhielt sich ihre ${ }^{67} \mathrm{Cu}$ -

Aktivität wie 4,7:93,4:1,9. Nach Owen (19) könnte es sich bei den 3 Proteinen um Caeruloplasmin, Hepatocuprein und Metallothionein handeln. Das ${ }^{67} \mathrm{Cu}$ des Metallothionein könnte in Hepatocuprein übergehen.

Co verhielt sich in unseren Versuchen analog. $30 \mathrm{~min}$ p. $i$. fanden wir 3 peaks.. Durch Vergleichsproteine mit bekanntem Molgewicht läßt sich für diese peaks ein Molgewicht von 120000,30000 und 9000 angeben. Sie entsprechen also denen des $\mathrm{Cu}(19)$, stehen jedoch in einer anderen quantitativen Relation zu einander. Nach $24 \mathrm{~h}$ ist das ${ }^{60} \mathrm{Co}$ ebenfalls fast nur noch im mittleren peak enthalten.

Bei adrenalektomierten Tieren findet man qualitativ das gleiche Verhalten. Die ${ }^{60}$ Co-Aktivität im niedermolekularen peak III ist jedoch $30 \mathrm{~min}$ p. i. relativ höher als in peak I und II (Abb. 1 a).

30 min. p.i. ist ${ }^{99}$ Mo hauptsächlich im niedermolekularen peak enthalten. Nach $24 \mathrm{~h}$ ist Mo praktisch nur noch im hochmolekularen peak nachzuweisen.

Bei adrenalektomierten Ratten wird Mo ebenfalls von peak III in peak I überführt. Peak II war jedoch weder nach $30 \mathrm{~min}$ noch nach $24 \mathrm{~h}$ zu sehen. Da aber bereits 30 min p.i. etwas Mo wie bei normalen Tieren in peak I war, fehlt bei adrenalektomierten Tieren peak II. Dieser Effekt scheint spezifisch für Mo zu sein (Abb. 1b).

30 min p.i. sind auch beim $\mathrm{Mn} 3$ peaks zu sehen. Vielleicht existiert noch ein weiterer zwischen peak I und II. Nach $24 \mathrm{~h}$ ist die ${ }^{54} \mathrm{Mn}$ Aktivität hauptsächlich im peak III mit dem niedrigsten Molgewicht enthalten. Zwischen normalen und nebennierenlosen Tieren bestand kein qualitativer Unterschied (Abb. 1 c).

Im Cytoplasma der Leber sind verschiedene ${ }^{65} \mathrm{Zn}$ enthaltene Fraktionen gefunden worden (8). Wir erhielten bei der Gelfiltration ebenfalls 5 unterscheidbare ${ }^{65} \mathrm{Zn}$ enthaltende Fraktionen. Das ${ }^{65} \mathrm{Zn}$-Spektrum unterscheidet sich jedoch wesentlich von den anderen Elementen. Eine ${ }^{65} \mathrm{Zn}$-Bindung in Proteinen mit niederem Molgewicht um 10000 erfolgt unter diesen Bedingungen praktisch nicht. Dies wurde auch von anderen (8) gefunden.

Nach $24 \mathrm{~h}$ ist die ${ }^{65} \mathrm{Zn}$-Aktivität aus den Fraktionen mit dem höchsten Molgewicht in ein Protein mit einem Molgewicht von etwa 20000 übergegangen. Dieser Proze scheint bei adrenalektomierten Tieren verlangsamt (Abb. 1d).

Bindung radioaktiver Spurenelemente an Proteine des Lebercytoplasma in vitro (Abb. 2).

Die zeitliche Veränderung des Aktivitätsspektrums bei den verschiedenen Spurenelementen läßt den Schluß $z u$, daf nach i. v. Injektion und der intrazellulären Aufnahme die Spurenelemente zunächst (reversibel) an be- 

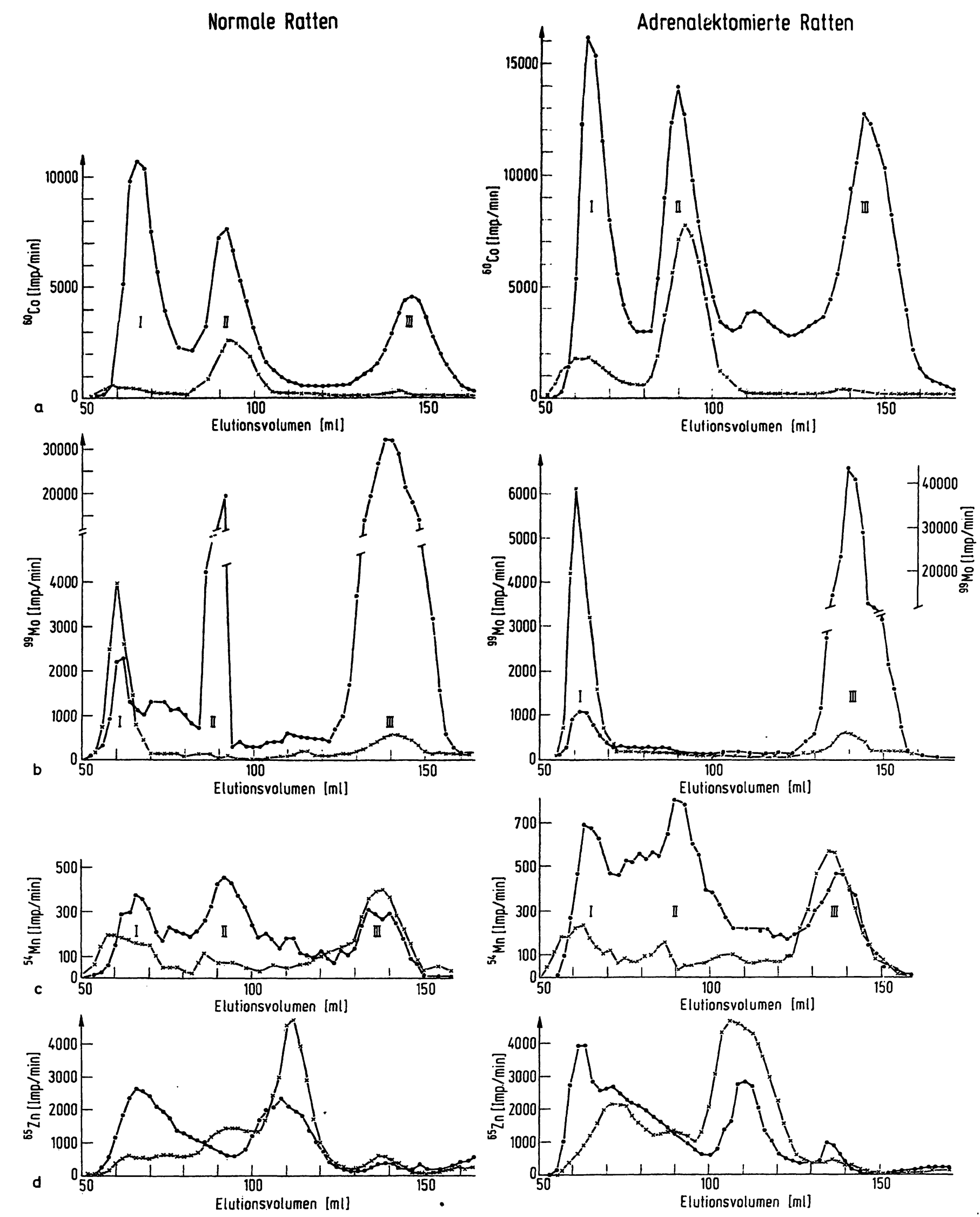

Abb. 1. Elutionsdiagramm des $100.000 \mathrm{~g}$-Überstandes von Leberhomogenaten normaler (links) und adrenalektomierter (rechts) Ratten (Sephadex G 100). $\longrightarrow 30$ min., $x-\times 24 \mathrm{~h}$ nach intravenöser Injektion der Radionuklide. Einzelheiten s. Methodik. 

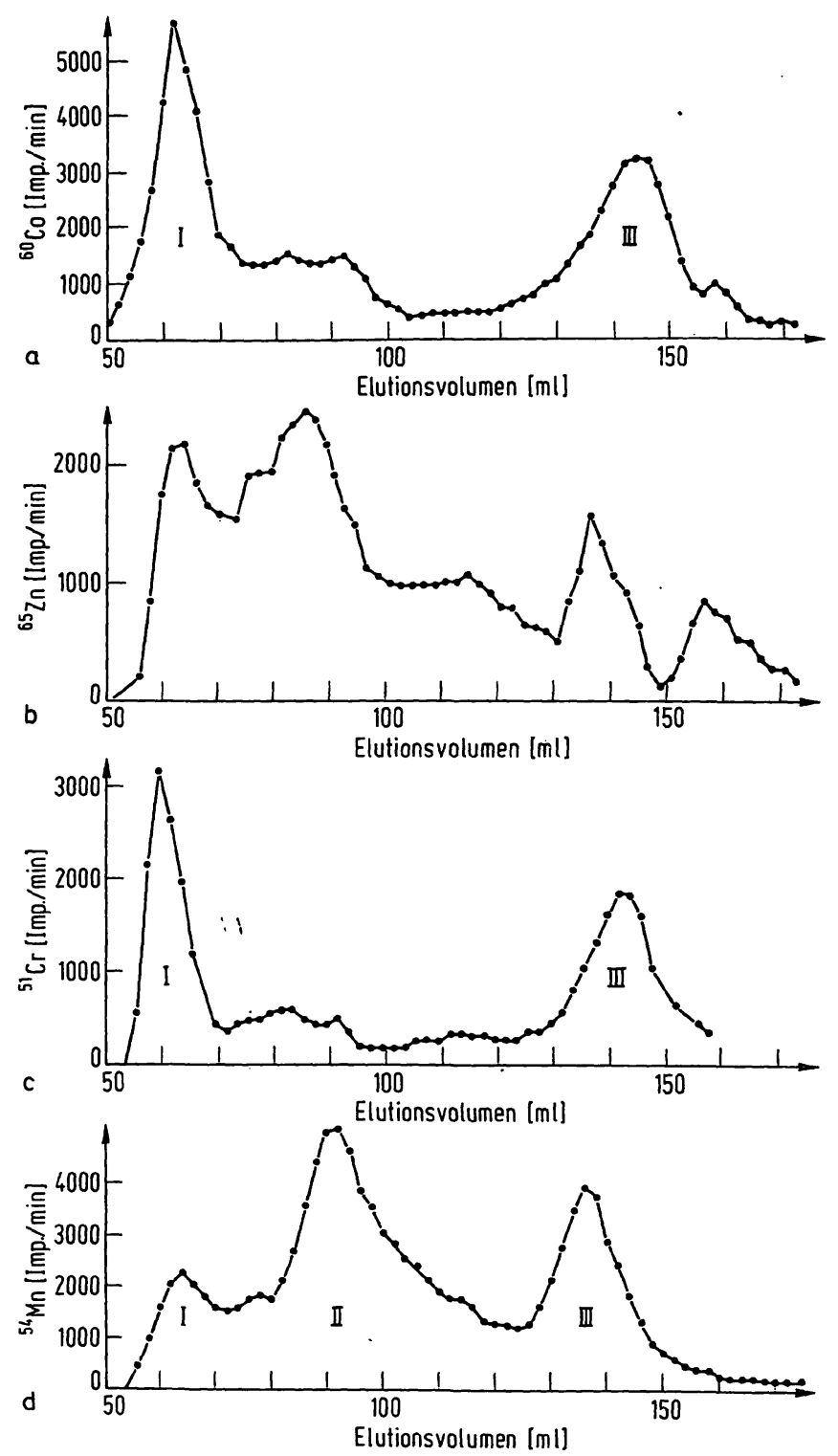

Abb. 2. Elutionsdiagramm des $100.000 \mathrm{~g}$-Überstandes von Leberhomogenaten normaler Ratten. Die Überstände wurden $1 \mathrm{~h}$ bei $37^{\circ} \mathrm{C}$ mit den verschiedenen Radionukliden geschüttelt und getrennt.

stimmte Proteine gebunden werden. Danach werden die Metalle aus diesen Proteinen (irreversibel) in andere Proteine eingebaut, was wahrscheinlich während der Biosynthese dieser Proteine erfolgt. Zur Überprüfung haben wir Leberhomogenat-Überstand mit radioaktiven Spurenelementen $60 \mathrm{~min}$ bei $37^{\circ} \mathrm{C}$ geschüttelt und in gleicher Weise fraktioniert.

Es zeigt sich, daß ${ }^{60} \mathrm{Co}$ nur in peak I und III gebunden wird (Abb. 2a). Die in vivo nach $24 \mathrm{~h}$ ausschließlich in peak II gefundene Aktivität könnte also bei der Synthese dieses Proteins eingebaut worden sein. (Oder ${ }^{60} \mathrm{Co}$ wird, was wenig wahrscheinlich ist, nur mit extrem langsamer Geschwindigkeit an das Protein im peak II angelagert. Da die Radionuklide trägerfrei injiziert wurden, ändern sich die intrazellulärẹn Konzentrationen nicht. Eine höhere Komplexbildungskonstante des Bindungsproteins im peak II scheidet als Ursache aus, die Aktivität wäre in diesem Falle sofort im peak II erschienen).

Für ${ }^{65} \mathrm{Zn}$ läßt sich das gleiche ableiten (Abb. $2 \mathrm{~b}$ ). In vitro zugegebenes ${ }^{65} \mathrm{Zn}$ wird hauptsächlich an hochmolekulare Proteine gebunden. Die in vivo erst später auftretende ${ }^{65} \mathrm{Zn}$-Aktivität in einem Protein mit 20000 Dalton könnte demnach auch erst bei dessen Biosynthese eingebaut worden sein.

Die nach Injektion von ${ }^{51} \mathrm{Cr}$ im Cytoplasma nachweis= bare ${ }^{51} \mathrm{Cr}$-Aktivität war sehr gering (wahrscheinlich wegen der hohen ${ }^{51} \mathrm{Cr}$-Bindung an Erythrocyten), so $\mathrm{daß}$ die ${ }^{51} \mathrm{Cr}$-Verteilung deshalb nur nach in vitro-Zugabe untersucht wurde (Abb. 2c). Dabei zeigte sich das gleiche Muster wie bei ${ }^{60} \mathrm{Co}$.

Nach ${ }^{54} \mathrm{Mn}$-Zugabe zur Überstandsfraktion erhält man das gleịche Aktivitätsmuster wie 30 min p.i. (Abb. 2d). $\mathrm{Da}$ alle peaks sofort vorhänden sind, besonders peak III, der $24 \mathrm{~h}$ p.i. fast die gesamte Aktivität enthält, scheint das Verschwinden von peak I und II $24 \mathrm{~h}$ p.i.auf einer Ausscheidung von ${ }^{54} \mathrm{Mn}$ zu beruhen. Das Zurückbleiben der Aktivität în peak III ließe sich mit einer höheren Mn-Komplexbildungskonstanten und einem irreversiblen Einbau von ${ }^{54} \mathrm{Mn}$ bei der Synthese eines Proteins erklären.

Bindung von Spurenelementen bei Cd-behandelten Tieren ( $\mathrm{Abb} .3$ )

Ein metallbindendes Protein kann durch Injektion von $\mathrm{CdCl}_{2}$ induziert werden (7). Bei Cd-behandelten Ratten findet man bereits $30 \mathrm{~min}$ p.i.einen höheren Teil der cytoplasmatischen ${ }^{65} \mathrm{Zn}$-Aktivität in einem Protein mit mittlerem Molgewicht (Abb. 3 a). Dieses Protein nahm bei in vitro-Inkubation mit ${ }^{65} \mathrm{Zn}$ keine Aktivität auf, d. $h .{ }^{65} \mathrm{Zn}$ wird wahrscheinlich nur bei der Synthese dieses Proteins eingebaut. Aus dem schnellen ${ }^{65} \mathrm{Zn}$-Einbau in diese Fraktion nach Vorbehandlung mit Cd kann man schließen, daß dieses Protein jetzt eine höhere Syntheserate aufweist.

Bei Cd-behandelten Tieren ist die ${ }^{60}$ Co-Aktivität 30 min p.i. sehr niedrig (Abb. 3b), was auf eine durch $\mathrm{Cd}$ gehemmte intrażelluläre Aufnahme hinweist. Nach 24 h ist ein wesentlich höherer Anteil als bei normalen Tieren im Protein mit mittlerem Molgewicht eingebaut. Daraus kann ebenfalls auf eine vermehrte Synthese dieses Proteins geschlossen werden.

Die ${ }^{54} \mathrm{Mn}$-Bindung an Proteine ist bei Cd-behandelten Tieren unverändert (Abb. 3c). Die am Mn-tumover beteiligten Proteine scheinen demnach durch $\mathrm{Cd}$ nicht induziert zu werden.

Ein Elutionsdiagramm der cytoplasmatischen Proteine von Rattenleber zum Vergleich mit den Abbildungen 1-3 enthält die Abbildung 4.

\section{Zur Funktion der cytoplasmatischen Bindungs-} proteine

Uber Bindungsart und Wertigkeit der Spurenelemente in diesen Bindungsproteinen läßt sich nichț aussāgen. 


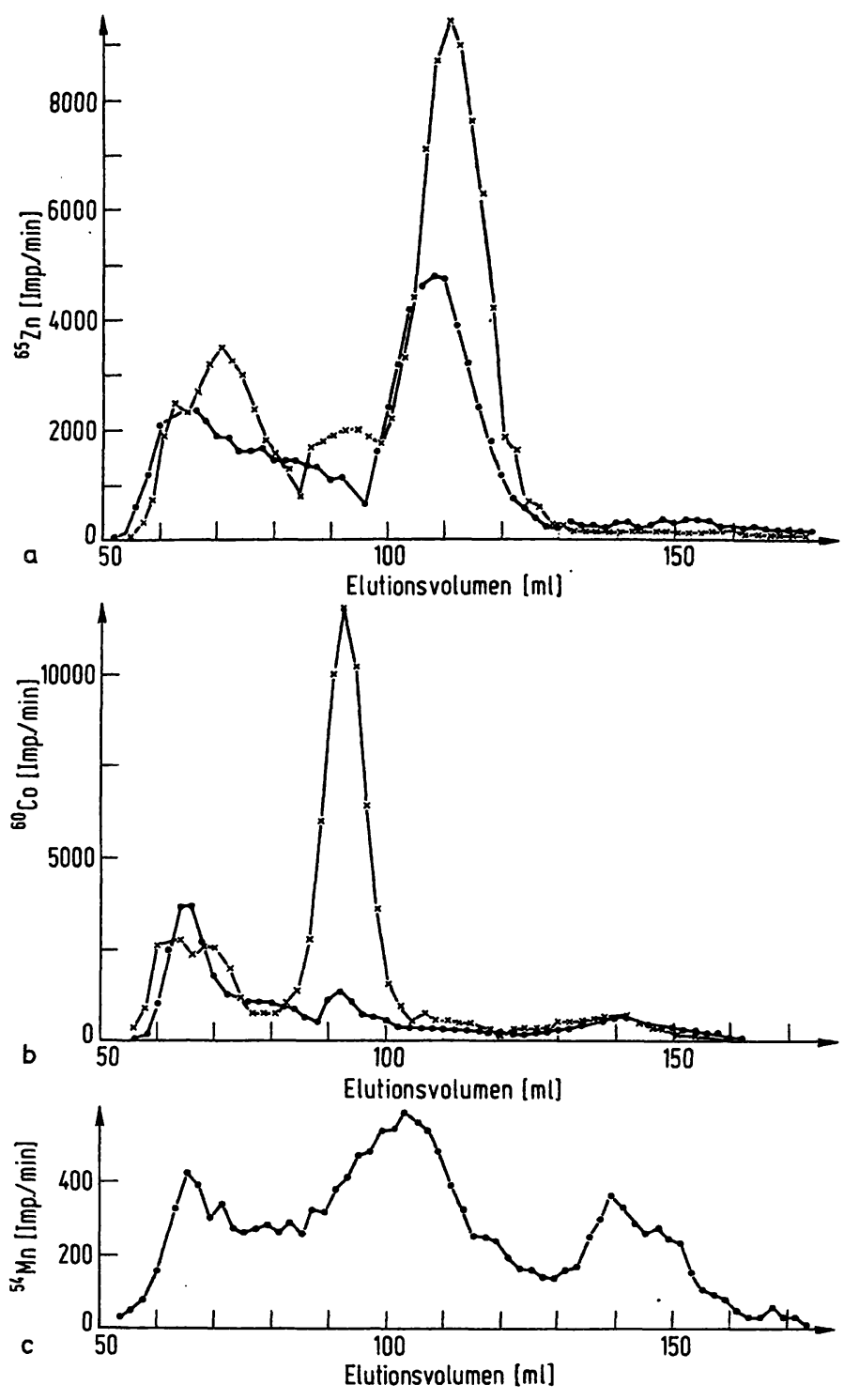

Abb. 3. Elutionsdiägramm des $100.000 \mathrm{~g}$-Überstandes von Leberhomogenaten Cd-behandelter Ratten. Den Tieren wurde $24 \mathrm{~h}$ vor der i. v.-Injektion der radioaktiven Spurenelemente $22 \mu \mathrm{mol} \mathrm{CdCl} / \mathrm{kg}$ i. p. injiziert. $\bullet-30 \mathrm{~min}$, $x-x 24$ h nach Injektion der Radionuklide.

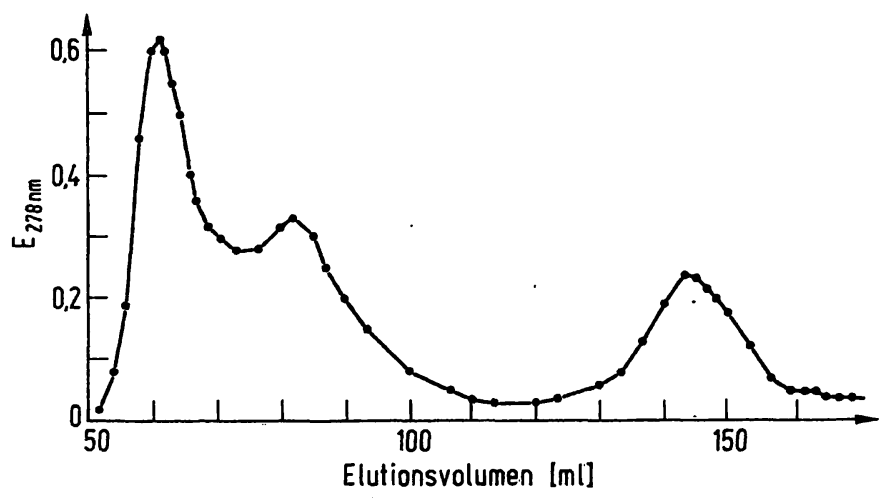

Abb. 4. Elutionsdiagramm des $100.000 \mathrm{~g}$-Überstandes eines Rattenleberhomogenates. Extinktionsmessung bei $278 \mathrm{~nm}$.
Die Struktur und Spezifität dieser Proteine sind ebenfalls noch ungeklärt. Wegen der hohen Komplexbildungskonstanten dieser Spurenelemente und der Existenz spezieller Bindungsproteine ist anzunehmen, daß diese Spurenelemente, wie für $\mathrm{Zn}$ bereits gezeigt (3), praktisch ausschließlich in gebundener Form vorliegen. Die Konzentration der freien Ionen, die im Gleichgewicht mit dem Chelat vorliegen müssen, ist wegen der Größe der Komplexbildungskonstanten praktisch zu vernachlässigen. Die quantitativen Zusammenhänge werden bei den Bindungsproteinen (X), die das Metallion (M) reversibel binden können, analog der Henderson-Hasselbalch-Gleichung $\mathrm{pM}=\mathrm{pK}+\log \frac{\mathrm{X}}{\mathrm{MX}}$ beschrieben, wobei $\mathrm{pM}$ der negative Logarithmus der Metallionenaktivität (M), pK der negative Logarithmus der Dissoziationskonstanten $\mathrm{K}$ und MX die Konzentration des Chelats ist. Die Änderung der Konzentration eines Spurenelements in einer Zellfraktion kommt daher praktisch nur durch $\mathrm{Zu}$ oder Abnahme von MX zustande. Als Ursache käme eine Änderung des pM oder eine Änderung des Gehalts von $\mathrm{X}$ in Frage. Eine Abnahme des $\mathrm{pM}$ ist möglich durch Mangel oder Verlust, eine Zunahme des pM durch Uberangebot (Vergiftung).

Der Gehalt an Bindungsproteinen (X) wäre durch Induktion oder Repression zu ändern. Auf diese Weise könnten die Nebennierenrinden-Hormone wirksam werden. Daß Nebennierenrinden-Hormone derartige Wirkungen entfalten können, ist bekannt. Darüberhinaus könnte auch die Änderung des pM, wie im Fall einer Injektion von $\mathrm{Zn}$ (oder Cd), nicht aber z. B. von Co oder $\mathrm{Ni}$ (7), die Synthese eines bestimmten Bindungsproteins induzieren.

Den intrazellulären Bindungsproteinen könnte eine Funktion beim Transport von Metallionen innerhalb der Zelle und als Speicher für Metallionen zukommen. Aus dem Speicher könnte ihr Einbau in Enzyme erfolgen, indem das Speicherprotein, welches das Metallion in nicht austauschbarer Form enthält, (in regulierbarer Weise) abgebaut wird. Durch die Bindung an spezielle Bindungsproteine könnte gleichzeitig eine Schutzfunktion ausgeübt werden, indem andere Enzymproteine mit wirksamen SH-Gruppen vor einer Inhibierung durch diese Metallionen geschützt werden. Die Induktion Metallionen-bindender Proteine nach Zufuhr größerer Mengen $\mathrm{Zn}$ oder $\mathrm{Cd}$ würde sich hier sinnvoll einordnen.

\section{Radionuklide im Serum (Abb. 5)}

Bereits 30 min nach i.v. Injektion war soviel ${ }^{54} \mathrm{Mn}$ und ${ }^{65} \mathrm{Zn}$ in die Organe aufgenommen worden, daß auf dem Elektropherogramm des Serums kaum noch Radioaktivität vorhanden war. Die sehr schnelle Aufnahme von ${ }^{65} \mathrm{Zn}$ in Leber und Niere nach i.v. Injektion hatten wir schon in früheren Versuchen gefunden (10). Die Bindung der Radionuklide an die elektrophoretisch trennbaren Serumproteine wurde deshalb nach in vitro-Zugabe der Nuklide untersucht. Lediglich nach i.v. Injektion 


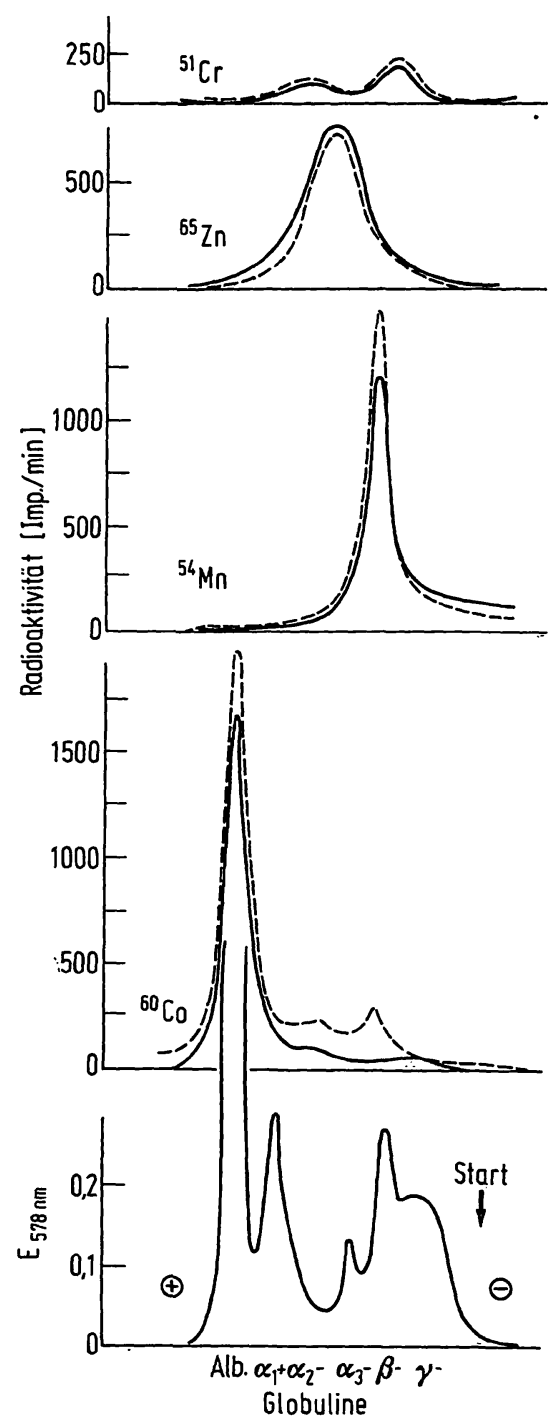

Abb. 5. Radio-Elektropherogramme von Rattenserum, das $60 \mathrm{~min}$ bei $25^{\circ} \mathrm{C}$ mit verschiedenen Radionukliden geschüttelt wurde.

- Serum von Normaltieren

- - - Serum von adrenalektomierten Tieren

$E_{578} \mathrm{~nm}$ : Photometrische Auswertung der Elektrophoresestreifen nach Färbung mit Ponceau S.

von ${ }^{60} \mathrm{Co}$ ließen sich noch Radio-Elektropherogramme mit ausreichender Aktivität herstellen, die die gleiche Verteilung der ${ }^{60} \mathrm{Co}$-Aktivität wie nach Zugabe in vitro ergaben. Das langsame Verschwinden von ${ }^{60} \mathrm{Co}$ (aus dem Serum-Albumin) stimmt überein mit einer langsameren intrazellulären Aufnahme des ${ }^{60} \mathrm{Co}$ im Vergleich zu ${ }^{65} \mathrm{Zn}$ und ${ }^{54} \mathrm{Mn}$ (nicht dargestellt).

${ }^{65} \mathrm{Zn}$ befand sich in einer breiten Bande im Bereich des $\alpha_{2}$-Globulins. Damit übereinstimmend hat Vallee (14) ein $\alpha_{2}$-Globulin mit einem $\mathrm{Zn}$-Gehalt von $400-700 \mu \mathrm{g} / \mathrm{g}$ isoliert, so daß es sich hierbei um das $\mathrm{Zn}$-bindende.Protein des Serums handeln kann. Der $\mathrm{Zn}$-enthaltende peak ist jedoch so breit, daß $\mathrm{Zn}$ auch im Transferrin gebunden sein kann. Bei adrenalektomierten Tieren ergáb sich die gleiche Verteilung.

Bei normalen und adrenalektomierten Ratten war das in vitro zugesetzte ${ }^{54} \mathrm{Mn}$ nur an Transferrin gebunden.

${ }^{51} \mathrm{Cr}$ wird bei normalen und adrenalektomierten Tieren an Transferrin und an $\alpha$-Globulin gebunden.

${ }^{60} \mathrm{Co}$ wird bei beiden Versuchsgruppen hauptsächlich im Albumin gefunden. Darüberhinaus erscheint bei adrenalektomierten Tieren in geringer Menge eine Cobindende Fraktion in den $\beta$-Globulinen, die nach ihrer Lage Transferrin sein kann.

Nach Ergebnissen von Aisen et al (20) sind Mn, Co und $\mathrm{Cr}$ als dreiwertige Kationen an Tyrosylreste unter Beteiligung von $\mathrm{HCO}_{3}^{-}$an das Apotransferrin gebunden. Die Oxidation von $\mathrm{Mn}^{2+} \mathrm{zu} \mathrm{Mn}{ }^{3+}$ erfolgt durch Luft- $\mathrm{O}_{2}$. Dies würde erklären, warum nach in vitro-Zugabe von ${ }^{54} \mathrm{Mn}$ dieses im Transferrin erscheint. Das zugegebene dreiwertige ${ }^{51} \mathrm{Cr}$ könnte direkt an Transferrin angelagert werden. Das schwer oxidierbare ${ }^{60} \mathrm{Co}$ findet sich nach in vitro-Zugabe im Albumin. Bei adrenalektomierten Tieren ist nach i.v. Injektion etwas $\mathrm{Co}$ an Transferrin gebunden. Co wird wahrscheinlich erst mit $\mathrm{H}_{2} \mathrm{O}_{2}$ in der Zelle $\mathrm{zu} \mathrm{Co}^{3+}$ oxidiert, bevor es an Transferrin gebunden werden kann. Bei adrenalektomierten Tieren scheint dieser Prozeß beschleunigt zu sein. Neben einer Bindung des $\mathrm{Co}^{3+}$ an Transferrin ist Albumin als Transportprotein für $\mathrm{Co}^{2+}$ anzusehen. İn dieses Schema paßt das Verhalten des $\mathrm{Zn}^{2+}$, das nach in vitro-Zugabe im $\alpha_{2}$-Globulin und nur in geringem Maße im Transferrin auftritt. Unter bestimmten Bedingungen ist es auch möglich, in vitro $\mathrm{Zn}^{2+}$ an isoliertes Transferrin zu binden (16). Vielleicht sind hierzu strukturelle Änderungen am Transferrin nötig. $\mathrm{Cu}$ ist sofort nach der Injektion an ein SerumProtein gebunden (5), wahrscheinlich Transferrin (16). Erst eine Stunde p.i. beginnt in der Leber der Cu-Einbau in Caeruloplasmin (5), dạs danach im Serum erscheint.

\section{Literatur}

1. Malmström, B. G. \& Neilands, J. B. (1964) Ann. Rev. Biochem. 33, 331-354.

2. Comar, C. L. \& Bronner, F. (1962) Mineral Metabolism, Vol. IIB Academic Press

3. Reinhold, J. G., Arslanian, M. \& Bitar, K. (1970) Biochim. Biophys. Acta 215, 430-437.

4. Huber, A. M. \& Gershoff, S. N. (1973) J. Nutr. 103, 1175 1181.

5. Owen jr., C. A. (1965) Amer. J. Physiol. 209, 900-904.

6. Evans, G. W. Majors, P. F. \& Cornatzer, W. E. (1970) Biochem. Biophys. Res. Comun. 40, 1142-1148.

7. Webb, M. (1972) Biochem. Pharm. 21, 2751-2765.

8. Shaikh, Z. A. \& Lucis, O. J. (1972) Arch. Environ. Health 24, 419-425.

9. Thiers, R. E. \& Vallee, B. J. (1957) J. Biol. Chem. 226 , 911-920.

10. Dorn, F. \& Günther, T. (1970) diese Z. 8, 618-620.

11. Günther, T. \& Alter, C. (1967) diese Z. 5, 67-72.

12. Schneider, W. C. \& Hogeboom, G. H. (1950) J. Biol. Chem. 183, 123-128.

13. Kägi, J. H. R. \& Vallee, B. L. (1961) J. Biol. Chem. 236, $2435-2442$ 
14. Pulido, P., Kägi, J. H. R. \& Vallee, B. L. (1966) Biochem. 5, 1768-1777.

15. Parisi, A. F. \& Vallee, B. L. (1969) Amer. J. Clin. Nutr. $22,1222-1239$.

16. Aasa, R., Malmström, B. G., Saltman, P. \& Vänngard, T. (1963) Biochim. Biophys. Acta 75, 203-222.

17. Eisinger, J. Fawaz-Estrup, F. \& Shulman, R. G. (1965) J. Chem. Phys. 42, 43-53.
18. Puscin, J. S. \& Gunter, T. E. (1972) Biochim. Biophys. Acta 275, 302-307.

19. Terao, T. \& Owen jr, C.A. (1973) Amer. J. Physiol. 224, $682-686$.

20. Aisen, P., Aasa, R. \& Redfield, A. G. (1969) J. Biol. Chem. $244,4628-4633$.
Prof. Dr. Th. Günther 1000 Berlin 33, Arnimallee 22 